\title{
Mathematical modeling of mini-CHP based on biomass
}

\author{
Aleksandr Mednikov ${ }^{1, *}$, Alexey Maksimov ${ }^{1}$, and Elina Tyurina ${ }^{1}$ \\ ${ }^{1}$ Melentiev Energy Systems Institute of Siberian Branch of the Russian Academy of Sciences, 130, Lermontov str., Irkutsk, \\ 664033, Russia
}

\begin{abstract}
One of the promising directions of small-scale distributed power generation for Russia is the use of biomass. The present work is devoted to studies of an mini-CHP based on multi-stage biomass gasification. Mathematical models of elements and mini-CHP in general based on technological schemes were constructed. The mathematical models were constructed with the software developed at Melentiev Energy Systems Institute of Siberian Branch of the Russian Academy of Sciences. The calculations were made for two sizes of internal combustion engines. Thus, we obtained the values of flow rates, temperatures of heat carriers at various points of flow charts of the plants.
\end{abstract}

\section{Introduction}

Currently small-scale distributed power generation is developing quite actively in Russia. At present there are about 50 thousand facilities of small-scale distributed power generation in the country [1]. Moreover, one of the key lines in the energy development which were stipulated in the energy strategy of Russia 2030 is smallscale distributed power generation. A special aim of the small-scale energy is to reliably supply energy to the regions located far from the network infrastructure. One of the promising directions of small-scale distributed power generation is the use of biomass [2].

Biomass includes a wide range of various types of biological materials: wood, agricultural waste, waste of wood processing and food industries, sea algae, grass, straw, bagasse, residual of sewerage, etc. However, the most easily accessible biomass types for energy production are wood and wood waste [3]. This can be explained by a number of reasons.

In rural areas biomass is still the main source of energy for heating and cooking, and is often the only accessible energy source. A great advantage of biomass is that it is accessible in each region, unlike coal or natural gas [4]. In our country there is a problem of waste left in the cutting areas, which leads to a considerable decrease in the efficiency of wood resource utilization. Furthermore, the wood left in the forest makes a negative impact on the environmental situation in the sites of felling, prevents growth of forest, leads to fires, development of pathogenic flora and increase in the population of harmful insects [4]. Also, the country has nature protection areas where the use of biomass is one of the most relevant ways to generate electricity.

Many regions of the country are facing the problem related to massive drying out of dark coniferous trees. This is caused by bacteriosis affecting deciduous and coniferous species. It affects fir and spruce woods consisting of eastern fir trees and Nordmann fir trees in Western Caucasus, common spruce woods in Northwest of Russia (watershed between the Northern Dvina and the Pinega), and spruce-fir wood stands consisting of Yezo spruce trees and East Siberian fir trees in Primorie Territory. In Siberia the fir woods consisting of Siberian fir trees in Western and Eastern Sayany, Kuznetsky Alatau, and Khamar-Daban are getting dried out. Large areas of drying out pine trees have been recently detected in East Siberia. The areas of drying out woods in different regions cover from several thousands and hundreds of thousands to several millions of hectares [5]. This wood is considered to be low-grade and subject to utilization.

Until now the problem of low-grade wood utilization has not been completely solved. In practice it is burned, however the removed wood is a precious natural feedstock which can meet energy needs in some sectors of the economy. Ultimate composition of burning mass of trunk timber [6] is virtually identical for all species [7]. As far as the composition of a decaying wood is concerned, it depends on the type of decay. There are two types of decay: corrosive and destructive. Under a destructive process of decay carbon content increases, whereas at a corrosive one - it remains without a change or decreases [7]. Therefore, the issue of wood waste and low-grade wood processing is important for Russia. It is necessary to adopt the existing technologies and develop new methods for processing [8-12].

The application of biomass-fired power plants or cogeneration plants of small and medium capacity allows us to organize energy supply to isolated territories and off-grid consumers [2, 13-19].

Gasification is the main technology for the use of biomass. Gasification is highly flexible in terms of feedstock utilization [20, 21]. In principle, gasification enables all types of biomass to be transformed into syngas [22, 23] which contains primarily hydrogen,

Corresponding author: mednikov@isem.irk.ru 
carbon monoxide, carbon dioxide and methane. Syngas can be used to produce synthetic types of fuel [24, 25], chemical substances and also it can be directly used to generate electricity and heat [9, 18, 26, 27]. Gasification has a high potential and high efficiency of biomass utilization process [20].

Moreover, some remote settlements use generator plants operating on liquid and gaseous fuel. Fuel for such stations is mainly delivered by air. Therefore, it is important to use the syngas produced from biomass as a fuel in the internal combustion engines.

To design a mini-CHP with biomass gasification it is necessary to make calculations aimed at the determination of the main operating indices of certain components of the mini-CHP. To this end it is necessary to develop mathematical models for individual components and the entire flowchart. Current stage of the research requires that preliminary calculations be conducted to determine temperatures and flow rates of heat carriers at the main nodes of the plant flowchart, which will further underlie a more detailed design calculation of the mini-CHP.

\section{Mathematical modeling of biomass- fired mini-CHP}

The paper addresses a biomass-fired mini-CHP with a gas-piston engine. The flowchart of the plant is presented in Fig.1. This flowchart is deliberately assumed to be redundant since in the process of calculation some ties (flows) between the components may "degenerate" (be excluded) and as a result we will obtain an optimal flowchart of the plant. The calculations are made for two variants of the mini-CHP design: 1) without heating the system water with exhaust gases in the gas-water heat exchanger (6); 2) with heating the system water with exhaust gases.

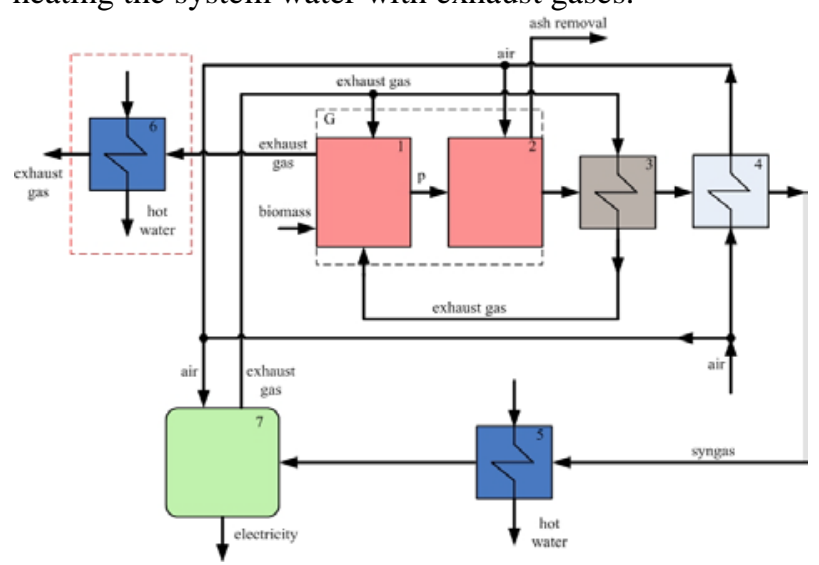

Fig. 1. Process flow chart of a mini-CHP. G - gasifier, 1 pyrolysis, 2 - gasification, 3 - gas-gas heat exchanger, 4 - gasair heat exchanger, 5, 6 - gas-water heat exchanger, 7 - gaspiston unit, $\mathrm{p}$ - pyrolysis products.

The input feedstock is deciduous wood with the following ultimate composition: 50.5\% C, 6.1\% $\mathrm{H}$, $42.4 \% \mathrm{O}, 0.6 \% \mathrm{~N}, 0.4 \%$ ash, $85 \%$ volatile matter, and heating value $-18.5 \mathrm{MJ}$ [7]. The dried wood biomass is delivered to a multistage gasifier. In the first stage (zone) the pyrolysis process occurs, it includes screw-type transportation of feedstock through the pyrolysis zone (1). Thus, we obtain pyrolysis products (pyrolysis gas, tars, and charcoal). Then the pyrolysis products go directly to the zone of gasifier (2). Here the tar products of pyrolysis are burnt in the oxidation zone of gasifier. The process of charcoal gasification occurs in a fixed bed with air. The oxidizer is supplied directly to the oxidation zone and the produced gas escapes from the bottom of the gasifier (down-draught). This gasifier design allows a reduction in the tar content in syngas [20]. Thus, we obtain syngas and ash at the gasifier outlet. Further, produced syngas passes through the systems of heat exchangers $(3-5)$ and goes to gaspiston unit (7) to generate electric energy. The gas-piston plant consists of a gas-piston engine with a cooling system, a charging generator and a starter. This research considers the existing gas-piston plants with an installed electric capacity of $30 \mathrm{~kW}$ and $100 \mathrm{~kW}$. Their main characteristics are presented in Table 1 . The exhaust gases of the engine are also utilized to heat pyrolyzer. The flowchart envisages air heating at the gas-piston engine inlet, since this is necessary for operation of such plants in the regions with cold climate.

Based on this flowchart the mathematical models of components and the entire CHP were constructed. The following requirements were imposed on the developed mathematical models of the CHP components:

1. Mathematical models should provide sufficiently accurate descriptions of real processes that run in the components of the plant;

2. Models should include relationships between input and output parameters of components and relationships between these variables and design characteristics of the components;

3. Models of components should include the relationships providing the check of the feasibility of the decisions made;

4. Mathematical models of components should meet the requirements for fast operation when used in further optimization calculations;

5. Mathematical models of components should agree with one another in detailing the processes running in them, and in input and output parameters.

Table 1. Main characteristics of gas-piston plants.

\begin{tabular}{|l|c|c|}
\hline \multicolumn{1}{|c|}{ Parameter } & Value & Value \\
\hline Rated capacity (long), $\mathrm{kW}$ & 30 & 100 \\
\hline $\begin{array}{l}\text { Maximum hourly power, } \\
\mathrm{kW}\end{array}$ & 33 & 110 \\
\hline Current type & $\begin{array}{c}\text { Alternating } \\
\text { three-phase }\end{array}$ & $\begin{array}{c}\text { Alternating } \\
\text { three-phase }\end{array}$ \\
\hline Rated voltage, $\mathrm{V}$ & 400 & 400 \\
\hline Rated frequency, $\mathrm{Hz}$ & 50 & 50 \\
\hline Rated current, $\mathrm{A}$ & 54 & 180 \\
\hline Gas pressure, $\mathrm{kg} / \mathrm{cm}^{2}$ & $0.5-5$ & $0.5-5$ \\
\hline
\end{tabular}

Mathematical model of a multistage gasifier represents a thermodynamic model [28] intended for the determination of the outlet temperature, composition and flow rate of syngas. 
Mathematical models of gas-gas, gas-air and gaswater heat exchangers include the equations of heat balance and heat transfer. The initial data are temperatures of heat carriers at the exchanger inlet, mass flow rates and design parameters. The calculation is aimed at the determination of temperatures of heat carriers at the heat exchanger outlet [29].

Mathematical model of a gas-piston engine is necessary to determine power of the engine, efficiency of the engine and hourly fuel consumption (syngas and air). The model uses the syngas composition obtained from the model of gasifier.

Power of an engine is determined from the equation

$$
N=Q_{H} \cdot G_{F} \cdot \eta_{e},
$$

where $Q_{H}$ - the lowest heating power of fuel, $G_{F}$ - fuel (syngas) consumption, $\eta_{e}$-efficiency.

Thermal calculation of gas-piston engine is carried out by using the mathematical model of GrinevetskyMazing and the method of Vibe [30].

To determine thermodynamic and transport parameters (enthalpy, entropy, specific volume, temperature, pressure, dynamic viscosity and heat conductance) of water, we use the subprograms developed at Energy Systems Institute of Siberian Branch of the Russian Academy of Sciences. They implement the nodal point method and are based on the relationships and tables of thermo-physical properties of water and water steam [31]. The thermodynamic properties of components of gas mixtures (enthalpy, heat conduction and specific volume) are determined using NIST polynomials [32].

The mathematical models were constructed with the software "System of Computer-based Construction of Programs" (SCCP) developed at Melentiev Energy Systems Institute of Siberian Branch of the Russian Academy of Sciences [33, 34].

The System of Computer-based Construction of Programs. The SCCP structure is chosen so as to automate all the most critical stages of the process of mathematical modeling of complex technological systems. The SCCP includes a graphical editor which allows construction of the flowcharts on the screen of a display by using images of individual components of the chart that were created in advance and construct the ties (material and energy flows) that relate the components with one another. This software makes it possible to automatically generate a program for calculation (in the Fortran language) of a complex plant on the basis of graphical representation of the flowchart and archives of mathematical models of its components. The SCCP applies a bichromatic graph to plan the computational process for the calculation of a mini-CHP flowchart. Two types of vertices are applied in the graph: black and white, and the relations are only possible between the vertices of different types. Black vertices correspond to variables, and white - to relations between the variables (equations and procedures). The ties between black and white vertices demonstrate entry of variables into the relations. If variable $i$ enters into relation $j$, then the $i$-th black vertex and the $\mathrm{j}$-th white vertex in the graph will be related by either an edge or an arc. If variable $i$ is input data for relation $\mathrm{j}$, then the edge is directed from black to white vertex. If variable $i$ is output data for relation $\mathrm{j}$, then the edge is directed from white to black vertex. In the event that the direction of the equations is not determined, which occurs before planning the computational process, the black and white vertices are connected by an undirected edge.

Since the description of certain components in the SCCP can involve both the subprograms with a composition of input and output values specified in advance and preliminarily undirected equations, the initial bichromatic graph corresponding to a system of relations, that describes the plant will be partly directed, i.e. it will have both arcs and edges.

The first problem to be solved for planning the computational process is the problem of complete orientation of the graph. For this purpose the SCCP has the following effective algorithms [33].

1. An algorithm for a search of black vertices whose removal makes the directed bichromatic graph of the system of equations free of loops. This algorithm is based on the formation of matrix "loops - black vertices" and a search for the minimum number of black vertices entering into all the loops. This, accordingly, reduces the number of iteratively calculated variables of the system of equations, considerably reduces the time of calculation and improves the convergence of the computational process.

2. An algorithm for an analysis of subsystems of linear balance equations (normally these are the material balance equations) allows us to select the initial data that belong to these subsystems in order to avoid their degeneracy. It is based on the detection of cycles in the undirected bichromatic graph of these subsystems and search for the minimum number of black vertices whose removal from the graph breaks all its cycles. The variables corresponding to these vertices should be assumed as initial data, which guarantees nondegeneracy of corresponding subsystems.

After the bichromatic graph becomes a complete directed graph the bicomponents are detected (sets of mutually attainable vertices). The white vertices entering into one bicomponent correspond to a closed subsystem of relations which should be solved iteratively. The relations that do not enter into the bicomponents can be calculated one by one. For each bicomponent the black vertices whose removal makes the graph free of loops are determined. Such vertices correspond to iteratively calculated variables.

The final stage of planning the computational process is ordering the white vertices of the graph, i.e. construction of a sequence of references to the relations such that all input data variables of the next relation enter either into the initial data specified before the calculation or into the iteratively calculated variables, or are already calculated from the equations that were already referred to before.

After the computational process is planned the program for calculation of a CHP is constructed in the algorithmic language FORTRAN.

The main design characteristics of two types of internal combustion engines are assumed from Table 1. 
The design characteristics of gas-gas and gas-water heat exchangers were preliminarily assumed on the basis of those commercially available. Electric capacity of the mini-CHP was obtained considering the efficiency of generator.

Using the mathematical models of the mini-CHP components we developed a mathematical model of the entire CHP. The mathematical model of mini-CHP is intended for the check calculation of the plant components and includes 79 input, 87 output and 3 iteration parameters. The model makes it possible to determine all material and energy flows (consumption, enthalpies, temperatures).

The syngas composition is $38.8 \% \mathrm{~N}_{2}, 10.2 \% \mathrm{CO}_{2}$, $0.9 \% \mathrm{Ar}, 1.4 \% \mathrm{H}_{2} \mathrm{O}, 45.8 \% \mathrm{CO}, 3 \% \mathrm{H}_{2}$.

Table 2. Results of the calculations of the main parameters of mini-CHP.

\begin{tabular}{|l|c|c|}
\hline \multicolumn{1}{|c|}{ Index and units } & Value & Value \\
\cline { 2 - 4 } & $\mathbf{3 0 ~ k W}$ & $\begin{array}{c}\mathbf{1 0 0} \\
\text { kW }\end{array}$ \\
\hline Wood flow rate, kg/s & 0.0084 & 0.0265 \\
\hline Syngas flow rate at gasifier outlet, kg/s & 0.017 & 0.055 \\
\hline Syngas temperature at gasifier outlet, K & 1138.03 & 1089.28 \\
\hline $\begin{array}{l}\text { Syngas temperature at exhaust gas } \\
\text { preheater outlet, K }\end{array}$ & 793.27 & 820.76 \\
\hline $\begin{array}{l}\text { Syngas temperature at air preheater } \\
\text { outlet, K }\end{array}$ & 486.7 & 532.11 \\
\hline Syngas temperature at engine inlet, K & 325.75 & 383,81 \\
\hline $\begin{array}{l}\text { Exhaust gas flow rate at engine outlet, } \\
\text { kg/s }\end{array}$ & 0.074 & 0.232 \\
\hline $\begin{array}{l}\text { Exhaust gas temperature at engine } \\
\text { outlet, K }\end{array}$ & 631.74 & 646.45 \\
\hline $\begin{array}{l}\text { Flow rate of exhaust gases at exhaust } \\
\text { gas preheater outlet, kg/s }\end{array}$ & 0.029 & 0.093 \\
\hline $\begin{array}{l}\text { Exhaust gas temperature at exhaust gas } \\
\text { preheater outlet, K }\end{array}$ & 891.74 & 849.33 \\
\hline Air temperature, K & 300 & 300 \\
\hline Air flow rate at engine inlet, kg/s & 0.056 & 0.18 \\
\hline Air temperature at engine inlet, K & 300 & 300 \\
\hline Air flow rate at air preheater inlet, kg/s & 0.021 & 0.066 \\
\hline Air flow rate at gasifier inlet, kg/s & 0.021 & 0.066 \\
\hline Air temperature at gasifier inlet, K & 649.73 & 636.54 \\
\hline Electric power of mini-CHP, kW & 30 & 100 \\
\hline Heat power of mini-CHP, kW & 30.47 & 98.47 \\
\hline $\begin{array}{l}\text { Specific fuel consumption for } \\
\text { electricity generation, kg/kW*h }\end{array}$ & 1.08 & 0.95 \\
\hline Electric efficiency of mini-CHP, \% & 19.51 & 20.38 \\
\hline Efficiency of mini-CHP, \% & 39.13 & 37.6 \\
\hline Capital investment, thousand doll. & 45 & 100 \\
\hline
\end{tabular}

Based on the flowchart given in Fig. 1 we constructed calculation scheme.

Calculations showed that the outlet temperature of exhaust gas from the pyrolysis reactor is quite high. Therefore, it was decided to add a gas-water heat exchanger (6) to the scheme.
Results of the calculations of the main parameters of mini-CHP are demonstrated in Tables 2.

Thus, we obtained the values of flow rates, temperatures of heat carriers at various points of flow charts of the plants.

The calculations were made for two sizes of internal combustion engines. The calculated heat capacity in terms of hot water makes up 4 and $13.31 \mathrm{~kW}$ in the variants without using the heat of exhaust gases and 30.47 and $98.47 \mathrm{~kW}$ in the variants that involved heat of exhaust gases.

$100 \mathrm{~kW}$ mini-CHP has a lower specific cost compared to $30 \mathrm{~kW}$ mini-CHP.

\section{Conclusion}

We developed mathematical models of a gas-piston engine, a gas-gas heat exchanger, a gas-water heat exchangers, a multistage gasifier and entire mini-CHP. The use of the SCCP makes it possible to further improve the mathematical model of the mini-CHP owing to a more detailed description of the processes in individual components.

The obtained results represent a preliminary estimate of the heat carrier parameters which can be used further in calculations.

The aim of further studies is to determine design parameters of the gasifier and heat exchangers as well as to optimize the mini-CHP parameters.

\section{Acknowledgements}

This work was carried out at Melentiev Energy Systems Institute of Siberian Branch of the Russian Academy of Sciences. Mathematical modeling of the gasifier was supported by Russian Foundation for Basic Research (RFBR) via grant № 18-08-01184 A. Part of the work is carried out within the framework of fundamental research program of the Russian Academy of Sciences for 2013-2020.

\section{References}

1. Energy strategy of Russia for the period up to 2030. http://minenergo.gov.ru/node/1026 (in Russian)

2. A.P. Belkin, A.V. Dubova, Energetic, 4, 13-17 (2016) (in Russian)

3. P. Lauri, P. Havlik, G.E. Kindermann, N. Forsell, H. Bottcher, M. Obersteiner, Energy Policy, 66, 19-31 (2014)

4. D.V. Tuntsev, R.G. Khismatov, M.R. Khayrullina, A.S. Savelyev, I.S. Romancheva, Actual directions of scientific research of the 21st century: theory and practice, 2, 459463 (2015) (in Russian)

5. V.V. Cherpakov, Current problems of forest complex, 35, 86-91 (2013) (in Russian)

6. T. Räisänen, D. Athanassiadis, Basic chemical composition of the biomass components of pine, spruce and birch.http://www.biofuelregion.se/UserFi les/file/Forest\%20Refine/1_2_IS_2013-0131_Basic_chemical_composition.pdf (2013) 
7. S.I. Golovkov, I.F. Koperin, V.I. Naydenov, Energy using of wood waste. Publishing Lesnaya promyshlennost, (Moscow, 1987) (in Russian)

8. G. Mao, H. Zou, G. Chen, H. Du, J. Zuo, Renewable and Sustainable Energy Reviews, 52, 1823-1833 (2015)

9. P. McKendry, Bioresource Technology, 83, 55-63 (2002)

10. D. Prando, F. Patuzzi, G. Pernigotto, A. Gasparella, M. Baratieri, Applied Thermal Engineering, 71, 152-160 (2014)

11. D. Russo, G. Macri, G. Luzzi, A. De Rossi, Procedia Social and Behavioral Science, 223, 849-856 (2016)

12. A. Trubetskaya, P.A. Jensen, A.D. Jensen, A.D. Garcia Llamas, K. Umeki, D. Gardini, J. Kling, R.B. Bates, P. Glarborg, Applied Energy, 171, 468-482 (2016)

13. M. Asadullah, Renewable and Sustainable Energy Reviews, 29, 201-215 (2014)

14. B. Buragohain, P. Mahanta, V.S. Moholkar, Renewable and Sustainable Energy Reviews, 14(1), 73-92 (2010)

15. K. Ericsson, S. Werner, Biomass and Bioenergy, 94, 5765 (2016)

16. A. Moiseyev, B. Solberg, A.M.I. Kallio, Energy, 76, 161167 (2014)

17. A. Perna, M. Minutillo, S.P. Cicconardi, E. Jannelli, S. Scarfogliero, Energy Procedia, 82, 687-694 (2015)

18. A. Sharma, Y. Shinde, V. Pareek, D. Zhang, Bioresource Technology, 198, 309-315 (2015)

19. R. Toonssen, N. Woudstra, A.H.M. Verkooijen, International Journal of Hydrogen Energy, 35, 7594-7607 (2010)

20. S. Heidenreich, P.U. Foscolo, Progress in Energy and Combustion Science, 46, 72-95 (2015)

21. S. Heidenreich, M. Muller, P.U. Foscolo, Advanced Biomass Gasification. New Concepts for Efficiency Increase and Product Flexibility ( $1^{\text {st }}$ ed. Elsevier, 2016)

22. T.K. Patra, P.N. Sheth, Renewable and Sustainable Energy Reviews, 50, 583-593 (2015)

23. A. Pandey, T. Bhaskar, M. Stöcker, R.K. Sukumaran, Recent Advances in Thermo-Chemical Conversion of Biomass (Elsevier, 2015)

24. M. Gądek, R. Kubica, E. Jędrysik, Computer Aided Chemical Engineering, 32, 55-60 (2013)

25. P. Trop, B. Anicic, D. Goricanec, Energy, 77, 125-132 (2014)

26. G. Chinnici, M. D’Amico, M. Rizzo, B. Pecorino, Renewable and Sustainable Energy Reviews, 52, 10251030 (2015)

27. A. Gómez-Barea, B. Leckner, A.V. Perales, S. Nilsson, D.F. Cano, Applied Thermal Engineering, 50, 1453-1462 (2013)

28. D.A. Svishchev, A.N. Kozlov, I.G. Donskoy, A.F. Ryzhkov, Fuel, 168, 91-106 (2016)

29. E.A. Tyurina, A.S. Mednikov, Advances in Energy Research, 3, 195-203 (2015)

30. I.I. Vibe, Thermal calculation of internal combustion engines (Chelyabinsk, 1972)

31. S.L. Rivkin, A.A. Aleksandrov, Thermophysical properties of water and steam (Publishing Energiya, Moscow, 1980) (in Russian)

32. NIST Chemistry WebBook. http://webbook.nist.gov/. Accessed 14 May 2018

33. A.M. Kler, N.P. Dekanova, S.K. Scripkin, A.V. Miheev, Z.R. Korneeva, A.B. Orehov, Mathematical modeling and optimization in operational control problems thermal power plants (Publishing Nauka, Novosibirsk, 1997) (in Russian)

34. A.M. Kler, A.S. Maximov, E.L. Stepanova, Proceedings of the ASME-ATI-UIT 2010 Conference Thermal and Environmental Issues in Energy Systems. Sorrento, Italy, 391-394 (2010) 